\title{
Front-face fluorescence spectroscopy combined with chemometrics to detect high proteinaceous matter in milk and whey ultrafiltration permeate
}

\section{Y. B. Ma and J. K. Amamcharla*}

Department of Animal Sciences and Industry/Food Science Institute, Kansas State University, Manhattan 66506

\section{ABSTRACT}

Proteinaceous matter can leak into the permeate stream during ultrafiltration (UF) of milk and whey and lead to financial losses. Although manufacturers can measure protein content in the finished permeate powders, there is currently no rapid monitoring tool during UF to identify protein leak. This study applied front-face fluorescence spectroscopy (FFFS) and chemometrics to identify the fluorophore of interest associated with the protein leak, develop predictive models to quantify true protein content, and classify the types of protein leak in permeate streams. Crude protein $(\mathrm{CP})$, nonprotein nitrogen $(\mathrm{NPN})$, true protein (TP), tryptone-equivalent peptide (TEP), $\alpha$-lactalbumin $(\alpha-\mathrm{LA})$, and $\beta$-lactoglobulin $(\beta-L G)$ contents were measured for 37 lots of whey permeate and 29 lots of milk permeate from commercial manufacturers. Whey permeate contained more TEP than did milk permeate, whereas milk permeate contained more $\alpha-\mathrm{LA}$ and $\beta$-LG than did whey permeate. The types of protein leak were thus identified for predictive model development. Based on excitation-emission matrix (EEM) of high- and low-TP permeates, tryptophan excitation spectra were collected for predictive model development, measuring TP content in permeate. With external validation, a useful model for quality control purposes was developed, with a root mean square error of prediction of $0.22 \%$ (dry basis) and a residual prediction deviation of 2.8. Moreover, classification models were developed using partial least square discriminant analysis. These classification methods can detect high TP level, high TEP level, and presence of $\alpha$-LA or $\beta-\mathrm{LG}$ with $83.3 \%, 84.8 \%$, and $98.5 \%$ cross-validated accuracy, respectively. This method showed that FFFS and chemometrics can rapidly detect protein leaks and identify the types of protein leak in UF permeate. Implementation of this method in UF processing plants can reduce financial

Received April 16, 2019.

Accepted June 20, 2019.

*Corresponding author: jayendra@ksu.edu loss from protein leaks and maintain high-quality permeate production.

Key words: deproteinized whey, milk permeate powder, tryptophan excitation spectra, partial least squares regression, partial least squares discriminative analysis

\section{INTRODUCTION}

Ultrafiltration (UF) is commonly used to fractionate proteins from skim milk and cheese whey, resulting in protein-rich retentate and lactose-rich permeate. The protein-rich retentate is further processed into milk protein concentrate or isolate and whey protein concentrate or isolate in powder forms. The lactoserich permeate of milk or whey is then processed into milk permeate powder (MPP) or deproteinized whey (DPW) powder, respectively. Because diafiltration is often performed during UF, the resulting permeate is diluted with various amounts of water, and consequently the permeate composition can vary widely among different manufacturers. Therefore, the composition of permeates is normally reported on a dry basis after the liquid permeate is concentrated, crystalized, and spray dried. According to the American Dairy Products Institute (ADPI, 2018), permeate powder contains at least $76 \%$ lactose and at most $7 \% \mathrm{CP}$, among other components. The CP may include NPN and some fractions of proteinaceous matter such as peptides and proteins from milk or whey (Walstra et al., 2005).

A fraction of proteinaceous matter can pass through the membrane into the permeate during UF. Because protein is the most profitable component in UF processing, leakage of protein into the permeate results in financial losses. In addition, the presence of protein in permeate powder can accelerate loss of quality during storage (Sithole et al., 2005). However, detection of CP in permeate powders occurs only after processing several batches at industrial scale, resulting in considerable lag time between the occurrence of a protein leak and the corrective action needed to repair it and prevent further leakage. Currently, at-line or in-line technolo- 
gies to monitor the quality of the permeate stream and detect abnormal levels of proteinaceous matter during UF are limited. Therefore, an accurate and rapid method is needed to detect protein leaks during UF.

Front-face fluorescence spectroscopy (FFFS) is known for its high sensitivity and ability to analyze turbid samples. Milk contains intrinsic fluorescent compounds such as tryptophan, nicotinamide adenine dinucleotide, vitamin A, and Maillard browning products, which are identified as fluorophores of interest to characterize dairy products (Shaikh and O'Donnell, 2017). Multivariate statistical analyses were used to extract quantitative, qualitative, or structural information from fluorescence spectra (Karoui and Blecker, 2011). Kulmyrzaev et al. (2005) used FFFS to characterize thermal effects on different milk proteins during pasteurization. To expand the applications of FFFS, supervised chemometric models can provide quantification and classification of nonfat dry milk, milk protein concentrate, and crude synthesis (Liu and Metzger, 2007; Fagan et al., 2011; Babu and Amamcharla, 2018).

Moreover, fluorescence spectroscopy can detect conformational differences in proteins (Vivian and Callis, 2001). The band shape, maximum intensity, and fluorescence lifetime are sensitive to polypeptide structures and chemical environment (Royer, 2006). Liu et al. (2018) used FFFS to study changes of protein structures caused by ultra-high-pressure homogenization. In the study by Liu and colleagues (2018), tryptophan was selected as the fluorophore of interest to study protein denaturation and aggregations. In some instances, UF membrane failure can lead to irreversible changes to the membrane porous size, which can lead to full protein $(\alpha-\mathrm{LA}$ and $\beta-\mathrm{LG}$ ) leakage through the membrane. Skim milk and whey UF feeds are also prone to proteolysis from enzyme residue and microbial growth, leading to various sizes of protein hydrolysate. Protein hydrolysates are small in molecular size, which allows them to pass through properly functioning UF membranes. The FFFS spectra may provide information on the types of protein leak in permeate from either full protein or peptides due to its specificity to protein conformations.

The objectives of this study were to identify the fluorophore of interest associated with the protein leak and to develop predictive models to quantify true protein (TP) content and classify the types of protein leaks in permeate streams.

\section{MATERIALS AND METHODS}

\section{Experimental Approach}

Milk and whey permeate powders were randomly collected from 2 commercial manufacturers (37 lots of
DPW and 29 lots of MPP) and analyzed for CP, NPN, and TP. Based on the ratio of TP to $\mathrm{CP}$, permeates were classified as either high- or low-TP permeates. In addition, analyses of tryptone-equivalent peptides (TEP), $\alpha$-LA, and $\beta$-LG were also carried out, to further understand the TP fraction of the permeates, and were used to identify types of protein leaks. Non-target FFFS analysis of permeates revealed the available fluorophores and identified the fluorophore of interest in representative high- and low-TP permeates. Chemometric models were developed based on the permeate classes and FFFS spectra of the target fluorophore. Detailed experimental procedures are included in the following sections.

\section{Permeate Samples}

Milk and whey permeate powders were randomly collected from 2 commercial manufacturers (37 lots of DPW and 29 lots of MPP). The permeate powder was reconstituted to $5 \%$ solution (wt/wt) at $25^{\circ} \mathrm{C}$ for $1 \mathrm{~h}$ using distilled water. The $5 \%$ concentration was selected to simulate the permeate stream coming from the UF process and was used for all subsequent analyses unless specifically notified. We designate solutions made from MPP as "milk permeate" and solutions made from DPW as "whey permeate." Collectively, we use "permeates" to indicate both milk and whey permeates.

\section{Ratio of True Protein to Crude Protein}

Levels of $\mathrm{CP}$ and NPN in the permeates were analyzed by the Kjeldahl nitrogen method (AOAC methods 991.20 and 991.21; AOAC International, 2016) in duplicates, with a nitrogen conversion factor of 6.38 . Level of TP was calculated as the difference between $\mathrm{CP}$ and NPN (expressed as protein equivalent). The $\mathrm{TP} / \mathrm{CP}$ ratio was calculated using the level of TP divided by the level of CP. The proportion of TP in $\mathrm{CP}$ determines the protein leak in permeates and classifies permeates as high- or low-true protein (HTP and LTP, respectively).

\section{Characterization of True Protein Fraction}

TEP Quantification. Levels of TEP in permeates were quantified using a fluorescence-based method developed by Udenfriend et al. (1972), with some modifications. In a microplate, $150 \mu \mathrm{L}$ of permeates and 50 $\mu \mathrm{L}$ of fluorescamine reagent (Thermo Fisher Scientific, Waltham, MA; $>99 \%$ purity) solution (10.8 $\mathrm{mM}$ in acetone) were added to each well. The microplate was shaken for $1 \mathrm{~min}$ in darkness before the fluorescence measurement using a spectrofluorometer (Biotek, Win- 
ooski, VT), with a $355-\mathrm{nm}$ excitation filter and 460-nm emission filter, at $25^{\circ} \mathrm{C}$. The level of TEP was quantified using a series of tryptone standards in duplicates and expressed as tryptone equivalent.

$\alpha-L A$ and $\beta-L G$ Analysis. We quantified $\alpha$-LA and $\beta$-LG using an HPLC-based method as described by Bonfatti et al. (2008), with modifications. Briefly, permeate powders were dissolved in $6 \mathrm{M}$ guanidine hydrochloride $(5 \% \mathrm{wt} / \mathrm{wt})$ at $25^{\circ} \mathrm{C}$ for $1 \mathrm{~h}$. The solution was filtered through a syringe filter (Millipore, Billerica, MA; Millex-FH, Polyethylene, $0.22-\mu \mathrm{m}$ pore size), and $8 \mu \mathrm{L}$ of the filtered sample was injected into an HPLC system equipped with a diode-array detector (HP 1050 series; Hewlett Packard, Palo Alto, CA). Separation was achieved using a silica-based packing C8 column (Zorbax 300SB-C8 RP, $3.5 \mu \mathrm{m}, 300 \AA, 150 \times 4.6 \mathrm{~mm}$ internal diameter; Agilent Technologies, Santa Clara, $\mathrm{CA}$ ) and a pre-column (Widepore C4, $4 \mathrm{~mm} \times 3.0 \mathrm{~mm}$; Phenomenex, Torrance, CA). A gradient elution was performed using 2 solvents. Solvent A consisted of $0.1 \%$ trifluoroacetic acid in water, and solvent B consisted of $0.1 \%$ trifluoroacetic acid in acetonitrile. Total analysis time was $45 \mathrm{~min}$, beginning with a linear gradient from 33 to $35 \%$ B in 5 min, from 35 to $37 \%$ B in $4 \mathrm{~min}$, from 37 to $40 \% \mathrm{~B}$ in $9 \mathrm{~min}$, from 40 to $41 \% \mathrm{~B}$ in $4 \mathrm{~min}$, followed by an isocratic elution at $41 \%$ B for $5.5 \mathrm{~min}$, then linear gradient from 41 to $43 \%$ B in $0.5 \mathrm{~min}$, from 43 to $45 \%$ B in $8 \mathrm{~min}$, and return linearly to the starting condition in $1 \mathrm{~min}$. The column was re-equilibrated under the starting conditions for $8 \mathrm{~min}$ before the next injection. The analysis was performed at a flow rate of $0.5 \mathrm{~mL} / \mathrm{min}$ at $45^{\circ} \mathrm{C}$. Detection was performed at 214 $\mathrm{nm}$, using the diode-array detector.

Pure whey protein standards $(>99 \%)$ of $\alpha-\mathrm{LA}$ and $\beta-L G$ were purchased from Sigma-Aldrich (St. Louis, $\mathrm{MO})$. External standard solutions were prepared in 6 $M$ guanidine hydrochloride, using the same procedure described above, and $\alpha$-LA and $\beta$-LG quantifications of permeate were achieved using calibration curves.

\section{Front-Face Fluorescence Spectroscopy Analysis}

Excitation-Emission Matrix of Permeate. Non-targeted FFFS analysis of representative HTP and LTP whey and milk permeates was achieved using the excitation-emission matrix (EEM). To collect the EEM, $7 \mathrm{~mL}$ of permeates was transferred into a quartz cuvette (Starna Cells Inc., Atascadero, CA). The frontface EEM was acquired at $25^{\circ} \mathrm{C}$ by recording the emission $\left(\boldsymbol{\lambda}_{\mathbf{E m}}\right)$ spectra from 300 to $500 \mathrm{~nm}$ (with $0.5-\mathrm{nm}$ interval) and corresponding excitation wavelengths $\left(\boldsymbol{\lambda}_{\mathbf{E x}}\right)$ from 220 to $360 \mathrm{~nm}$ (with 10-nm interval) using a spectrofluorometer (LS-55; Perkin Elmer, Waltham,
MA). The emission and excitation slit width was set at $4 \mathrm{~nm}$, scan speed was set at $100 \mathrm{~nm} / \mathrm{min}$, and the measurement angle was $56^{\circ}$.

Excitation Spectra of Tryptophan. After preliminary examination of the EEM, tryptophan was selected as the fluorophore of interest. Tryptophan front-face excitation spectra $\left(\lambda_{\mathrm{Em}}\right.$ at $\left.340 \mathrm{~nm} ; \lambda_{\mathrm{Ex}} 200-300 \mathrm{~nm}\right)$ were collected using the spectrofluorometer at $25^{\circ} \mathrm{C}$. The emission and excitation slit width was set at 5 $\mathrm{nm}$, the scan speed was set at $300 \mathrm{~nm} / \mathrm{min}$, and the measurement angle was $56^{\circ}$. For each sample, triplicate analysis was carried out, and the scans were averaged to improve signal-to-noise ratio.

\section{Spectral Preprocessing and Principal Component Analysis}

The tryptophan fluorescence excitation spectra were normalized using the standard normal variate technique before chemometric analysis. This normalization process unified the fluorescence intensity scale and minimized bias for the subsequent chemometric analysis ( $\mathrm{Li}$ et al., 2015). Principal component analysis (PCA) was applied to reduce the dimensionality and redundancy in the data set, and PCA similarity plots were generated to provide visualization of permeate sample clustering.

\section{Partial Least Squares Regression and Discriminative Analysis}

Partial least squares regression (PLSR) is a supervised chemometric algorithm that has been widely used to model spectral data (Diez et al., 2008). A PLSR extracts latent variables from spectral data and maximizes their covariance to the reference values. In this study, TP content was predicted using PLSR, with standard normal variate-normalized tryptophan excitation spectra as input. The original permeate data set was partitioned randomly to a calibration set $\left(\mathrm{n}_{\text {cal }}=\right.$ $47)$ and a validation set $\left(\mathrm{n}_{\text {val }}=19\right)$. The calibration models were developed and validated using leave-oneout cross-validation. The cross-validated model was evaluated by root mean square error of cross-validation (RMSECV), as shown in Equation [1]. Residual prediction deviation (RPD) was calculated by dividing the RMSECV by the standard deviation of the reference data set, to estimate model prediction power (Williams and Norris, 2001). The calibration model was also externally tested by predicting the validation set. The root mean square error of prediction (RMSEP) and RPD of the prediction confirmed the model validity on unseen samples, which can estimate the future model applicability of TP quantification (Wold et al., 2001): 


$$
R M S E C V \text { or } R M S E P=\sqrt{\frac{\sum_{j=1}^{n}\left(y_{j-} \hat{y}_{j}\right)^{2}}{n}},
$$

where $\hat{y}$ is the predicted value from cross-validation $(\mathrm{CV})$ or prediction $(\mathrm{P})$ of the $j$ th sample, $y$ is the reference value of the $j$ th sample, and $n$ is sample size.

Classification models using partial least squares discriminative analysis (PLS-DA) were developed to identify the types of protein leak. Partial least squares discriminative analysis is a supervised classification method based on linear discriminant models (Lenhardt et al., 2015). The reference variables in PLS-DA are dummy variables indicating whether a sample belongs to a certain class. In this study, the reference classes used for PLS-DA included TP levels, TEP levels, and $\alpha$-LA or $\beta$-LG presence or absence. Using the same predictor as PLSR, the classification models were cross-validated using leave-one-out cross validation. Accuracy, sensitivity, and specificity were calculated to evaluate model performance based on Gromski et al. (2014). For all classifications in this study, the positive class indicates high TP, high TEP, or presence of $\alpha$-LA or $\beta$-LG. The negative class indicate low TP, low TEP, or absence of $\alpha$-LA or $\beta$-LG.

\section{Statistical Analysis}

Unpaired $t$-tests were used to compare means of CP, $\mathrm{TP}$, and TEP between milk and whey permeates. The $t$-tests, chemometric visualization, and modeling were performed using RStudio (R Core Team, 2019; version 1.1.442; RStudio, Boston, MA) with the Caret and pls packages (Mevik and Wehrens, 2007; Kuhn, 2008).

\section{RESULTS AND DISCUSSION}

\section{Proteinaceous Matter Characterization}

Proteinaceous Fractions of Permeate Powders. Even though UF has been a common practice in dairy food processing, protein analysis of permeate powders has not been widely reported. As shown in Figure 1A, the average NPN contents in whey and milk permeate were found to be 2.51 and $2.35 \%$ (expressed as proteinequivalent on dry basis), respectively, with no significant difference $(P>0.05)$. Smith et al. (2016) reported the NPN in UF cheese permeate to be between 2.5 to $3.6 \%$ (dry basis) using the Kjeldahl-based method. The variation in NPN is related to the cheese-making process, and low-pH whey with more proteolysis can lead to increase of soluble nitrogen. Smith et al. (2016) also measured TP in the whey and milk permeates, ranging from not detectable to $0.003( \pm 0.003 \% \mathrm{SD})$, showing negligible TP presence in permeate powders. However, the pilot-scale permeate manufacturing process featured in that study was designed for research purposes. The minimal TP content can represent the ideal situation of UF efficiency. Frankowski et al. (2014) collected spray-dried and liquid whey permeates from commercial manufacturers. Although some permeates had no TP detected, the reported maximum TP found in that study was $0.88 \%$ (dry basis). In the present study, whey and milk permeates showed higher TP contents, with averages $( \pm \mathrm{SD})$ of $0.69 \pm 0.48$ and 1.17 $\pm 0.51 \%$, respectively $(P<0.05)$. The TP contents were higher than previously reported values because the samples were collected from commercial production runs. Due to the large variation in TP, CP in whey and milk permeate ranged from 2.51 to $3.40 \%$ and 2.72 to $3.58 \%$, respectively, with no significant difference $(P>$ $0.05)$. The variation in TP content from whey and milk permeates showed that protein leakage may have occurred in some of the samples considered in our study.

A relatively large variation in $\mathrm{TP}$ indicated existence of subgroups among the permeates. The TP/CP ratio was calculated to highlight TP differences while minimizing the variation in $\mathrm{CP}$, as shown in Figure 1B. Figure 2 shows the TP/CP ratio density plot of the permeates as a bimodal distribution with 2 distinct groups. The mean of the $\mathrm{TP} / \mathrm{CP}(\mu=0.25)$ was used as a cutoff to classify permeates as LTP permeate (where $\mathrm{TP} / \mathrm{CP}<0.25, \mathrm{n}=34$ ) and $\mathrm{HTP}$ permeate (where $\mathrm{TP} / \mathrm{CP}>0.25, \mathrm{n}=32$ ). Figure $1 \mathrm{~B}$ illustrates protein fractions of LTP and HTP. The NPN fraction of LTP and HTP was similar to the prior comparison, but a larger difference was observed in the TP fraction, indicating the occurrence of protein leak in the HTP group. Among the LTP permeates, there is still some proteinaceous matter in the sample, indicating the presence of proteins or peptides with an average TP content of $0.46 \%$.

Tryptone-Equivalent Peptide Analysis. The average peptide content of permeates using tryptone as standard is shown in Figure 3A. The fluorometric method used a primary amine reaction to attach a fluorescence dye and quantify peptides or proteins using the corresponding standard. Tryptone has been used as the standard measurement of peptide content and degree of protein hydrolysis in dairy foods (Minervini et al., 2003; Oh et al., 2013). Therefore, tryptone equivalence can be used as an effective measurement of peptide content in permeates. It should be noticed that the TEP quantified in permeates were assumed to be less than $10 \mathrm{kDa}$ because the samples have gone through a typical UF process. The leak of proteinaceous matter as TEP $(<10 \mathrm{kDa})$ does not indicate membrane performance failures, but it may correspond to proteolysis 


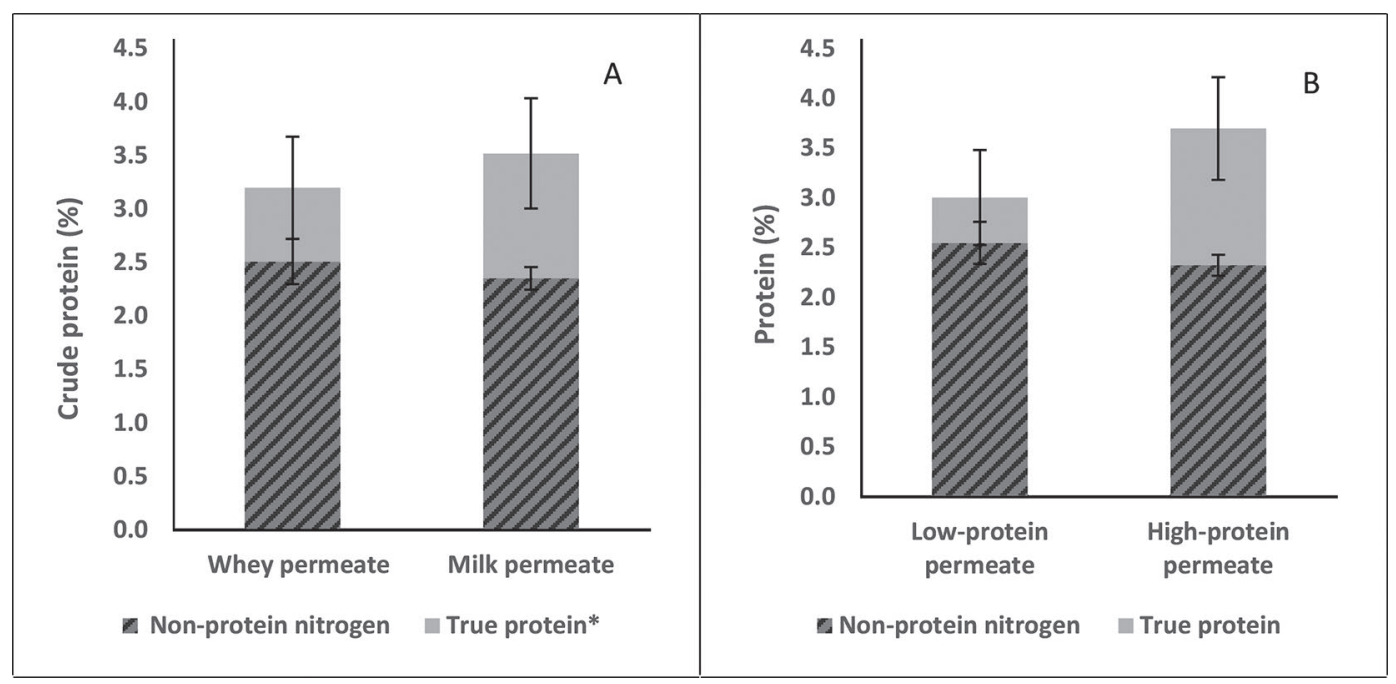

Figure 1. Protein fraction comparison between (A) whey and milk permeates and (B) low-true-protein and high-true-protein permeates. Error bars represent SD of non-protein nitrogen and true protein, respectively. ${ }^{*} P<0.05$.

before UF. Whey permeate showed an average TEP content $( \pm \mathrm{SD})$ of $0.37 \pm 0.04 \%$ tryptone equivalent and milk permeate showed an average TEP content $( \pm \mathrm{SD})$ of $0.32 \pm 0.07 \%$ tryptone equivalent; $P<0.05$. The higher TEP content in whey permeate agreed with the proteolysis process from cheese-making. Residual rennet and cheese culture are both proteolytic (Fox, 1989). Especially after whey draining, timely inactivation of rennet and bacteria are needed to minimize proteolysis occurrence. On the other hand, to produce milk permeate, skim milk is directly processed as the feed for UF, so less exposure of proteolytic enzymes or bacteria will occur in UF of milk.

Two subgroups with high- and low-TEP contents are shown in Figure 3B. The subgrouping was achieved by plotting TEP content on a density plot. In Figure 4, the distribution of the TEP content is shown, and high- and low-TEP permeates were classified based on the average dry-basis content of $0.35 \%$. Subgrouping shows that 25 out of 37 whey permeates were classified as high-TEP permeates, whereas only 5 milk permeates were in the high-peptide category. On the other

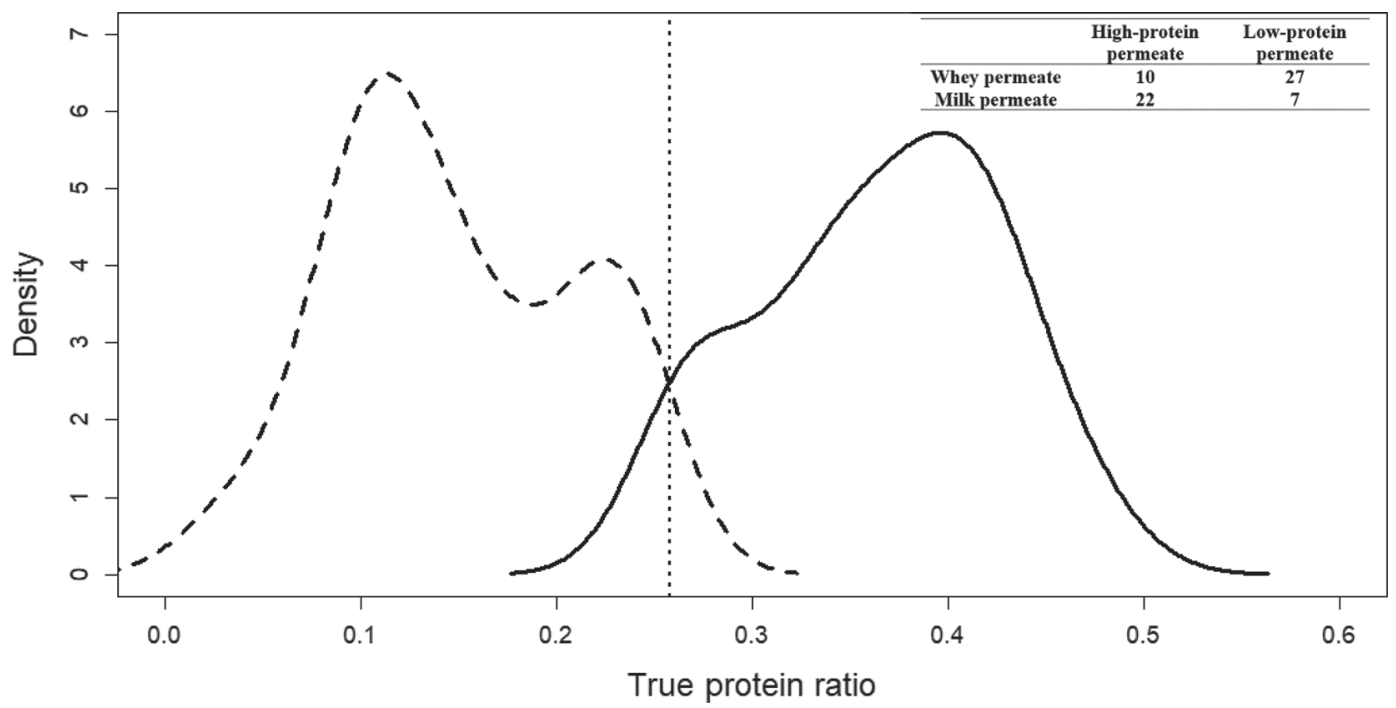

Figure 2. Density plot of true protein ratio $(\mathrm{n}=66)$. The dashed line represents the distribution of low-protein permeate $(\mathrm{n}=34)$, and the solid line represents the distribution of high-protein permeate $(\mathrm{n}=32)$. The vertical dotted line represents the mean of the overall true protein ratio $(\mu=0.25)$. 

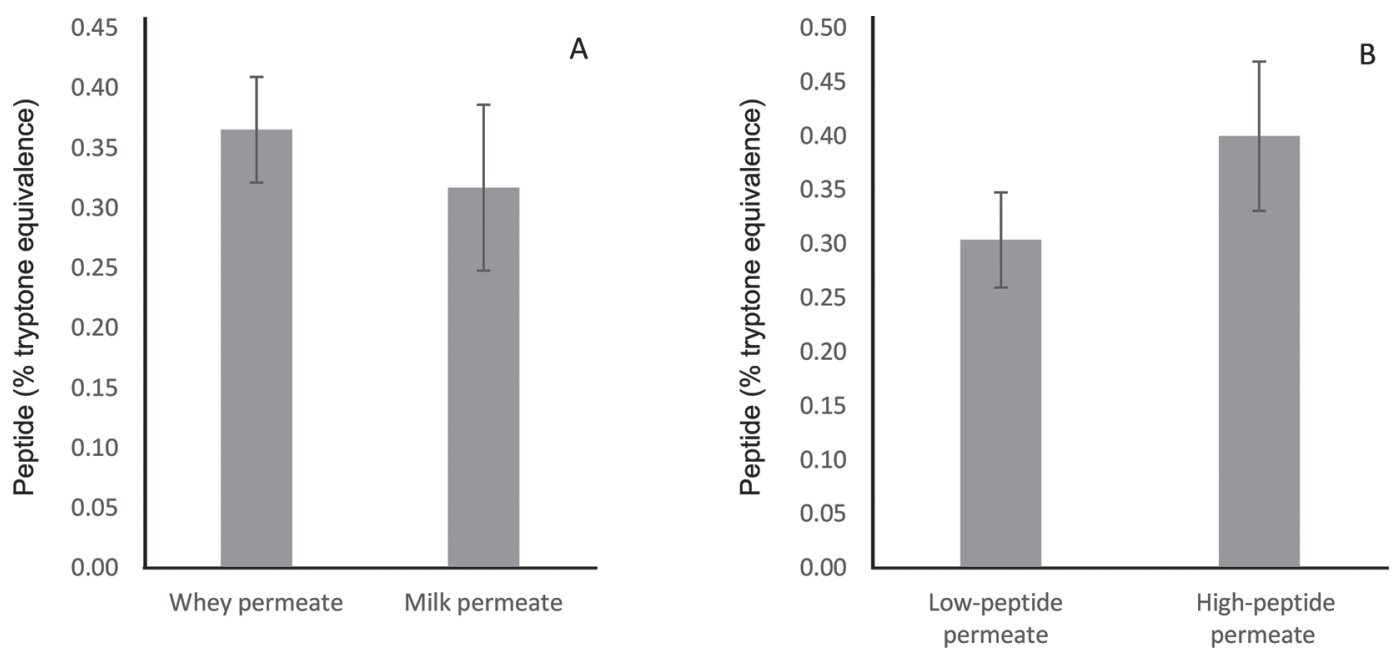

Figure 3. Tryptone-equivalent peptide comparison between (A) whey and milk permeates and (B) low-peptide and high-peptide permeates. Error bars represent SD.

hand, 24 out of 29 milk permeates were classified as low-peptide permeates, indicating fewer occurrence of proteolysis. The high- and low-peptide permeate classes allowed supervised chemometric model development to predict the types of protein leak.

$\alpha-L A$ and $\beta-L G$ Analysis. An HPLC analysis of $\alpha-\mathrm{LA}$ and $\beta-\mathrm{LG}$ revealed the full protein presence in the permeates. Overall, whey permeates had no detectable $\alpha$-LA or $\beta$-LG. In milk permeate $(\mathrm{n}=29), 25$ and 17 lots contained detectable levels of $\alpha-\mathrm{LA}$ and $\beta$-LG, respectively. The detection limits of the method by Bonfatti et al. (2008) were $0.6 \mu \mathrm{g}$ for both whey protein fractions. On a dry basis, as shown in Figure 5, more $\alpha$-LA $(\mu=0.27 \%)$ than $\beta$-LG $(\mu=0.04 \%)$ was found in the milk permeate, and the presence of full proteins indicated another type of protein leak. The UF membrane contains a pore distribution with the average pore cutoff reported as $10 \mathrm{kDa}$; however, depending on processing conditions and the chemical environment of the feed (milk and whey), the membrane pore cutoff is altered and, consequently, some whey proteins can pass through. We see in Figure 5 that more $\alpha$-LA $(\sim 14 \mathrm{kDa})$ than $\beta$-LG $(\sim 18 \mathrm{kDa})$ was detected in the permeate, agreeing with the hypothesized pore cutoff expansion

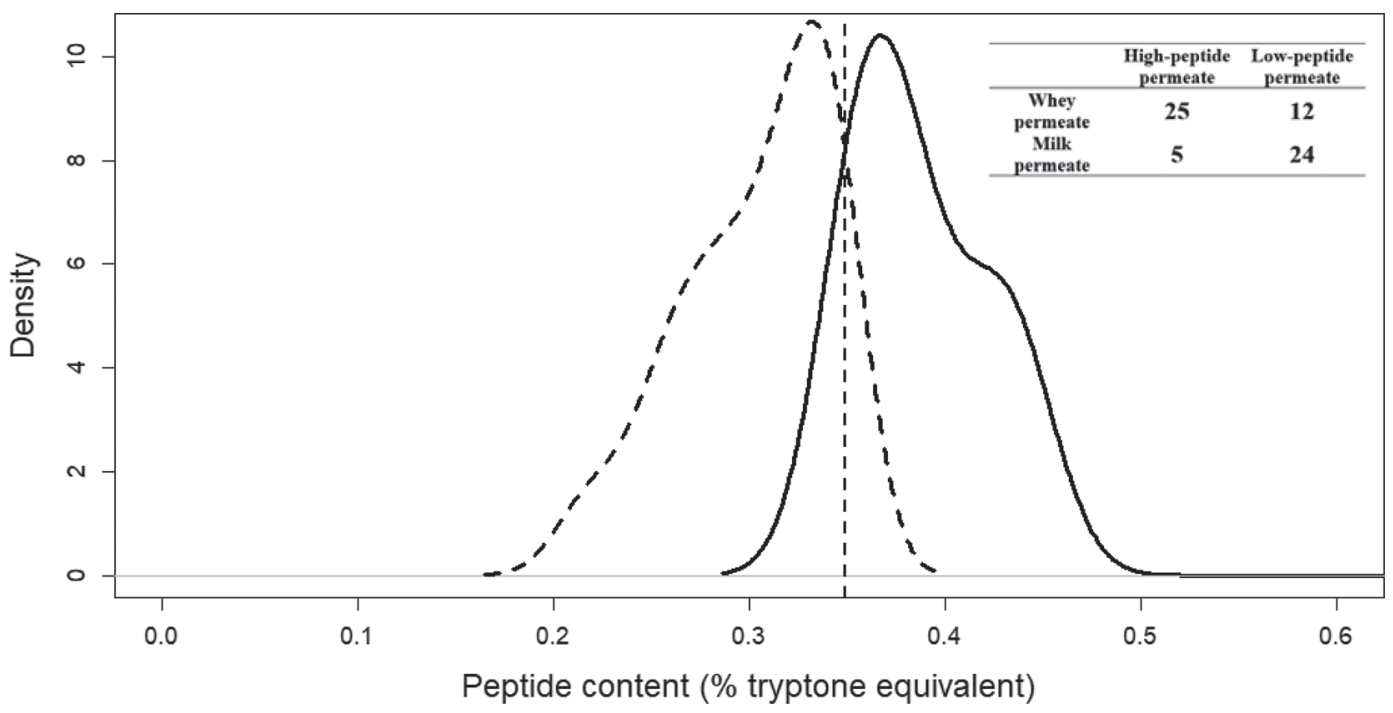

Figure 4. Density plot of tryptone-equivalent peptide content $(\mathrm{n}=66)$. The dashed line represents the distribution of low-peptide permeate $(\mathrm{n}=31)$, and the solid line represents the distribution of the high-peptide permeate $(\mathrm{n}=35)$. The vertical dotted line represent the mean of the overall peptide content ( $\mu=0.35 \%$ tryptone equivalent). 


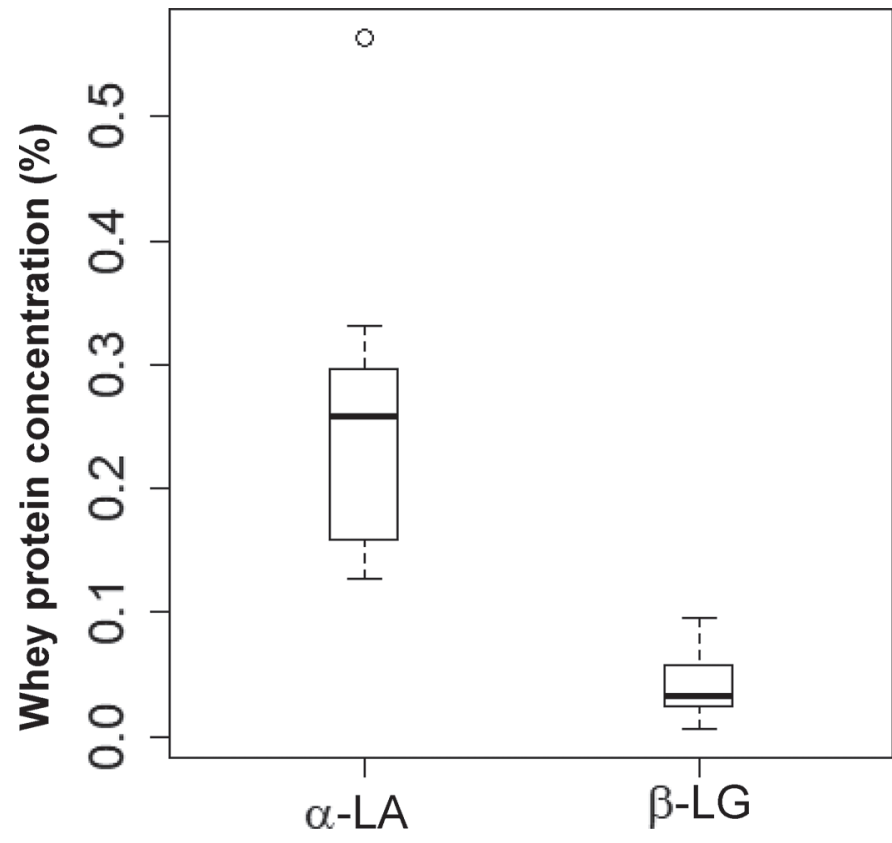

Figure 5. Whey protein fractions: $\alpha$-LA $(\mathrm{n}=25)$ and $\beta$-LG (n $=17$ ) presence in permeate samples. Boxes represent the second and third quartiles, or the interquartile range (IQR); the horizontal line inside indicates the median value of $\alpha$-LA or $\beta$-LG, respectively. The horizontal lines at the top and bottom of the box represent the lower (25th percentile) and upper (75th percentile) quartiles. Whiskers indicate the minimum and maximum values, or $1.5 \times \mathrm{IQR}$ if outliers (defined by $>1.5 \times$ IQR, indicated in circles) are present.

for smaller proteins during UF. Considering the similar TP content between whey and milk permeates, more TP fractions of whey permeates may come from peptide rather than full whey protein, in agreement with the TEP data. Milk permeates contained full $\alpha$-LA and $\beta$-LG, which contributed to the TP content shown in Figure 1. For chemometric predictions, the presence or absence of $\alpha$-LA or $\beta$-LG was used as a binary class for the permeate samples.

The bimodal distribution of TP and $\mathrm{CP}$, presence of peptides, and presence of $\alpha$-LA, and $\beta$-LG indicated that protein leakage occurred in some permeates during the membrane processing. The types of protein leak can vary based on whether whey or milk is the UF feed material. Subsequent FFFS analysis aimed to identify the fluorophore of interest associated with TP presence in permeates. Chemometric analysis will further model spectral data to predict true protein contents and identify the sources of protein leakage.

\section{Fluorescence Spectra of HTP and LTP Permeates}

Excitation-Emission Matrix of Permeate Stream. The EEM (Figure 6) characterizes repre- sentative HTP and LTP permeates of whey and milk in terms of differences and similarities in their fluorescence intensities at various excitation and emission wavelengths. We found 4 fluorescence maxima on the EEM (Figure 6) of permeates, corresponding to 3 fluorophores commonly found in permeates. In Figure $6 \mathrm{~A}$ and $\mathrm{B}$, riboflavin appeared in HTP and LTP whey permeates at fluorescence maxima $\lambda_{\mathrm{Ex}} 270 \mathrm{~nm}$ and $\lambda_{\mathrm{Em}}$ $430 \mathrm{~nm}$. Andersen and Mortensen (2008) summarized common fluorophores in dairy products, and riboflavin was reported to have 3 maxima at $\lambda_{\mathrm{Ex}} 270,360$, and $450 \mathrm{~nm}$ and $\lambda_{\mathrm{Em}} 430 \mathrm{~nm}$. However, riboflavin showed similar peak intensity for both HTP and LTP whey permeate, and consequently we did not select riboflavin as the fluorophore of interest for protein leak detection. Fluorescence intensities of the Maillard browning products are found in a range from $\lambda_{\mathrm{Ex}}$ from 310 to $350 \mathrm{~nm}$ and $\lambda_{\mathrm{Em}}$ from 380 to $430 \mathrm{~nm}$ for whey permeate (Figures 6A and 6B). Fluorescence of Maillard browning products in dairy products have been widely reported to characterize heat treatments and storage changes in dairy foods. Kulmyrzaev et al. (2005) applied FFFS for heat-induced changes of protein concentration in pasteurized milk, and Babu and Amamcharla (2018) measured Maillard browning FFFS spectra to characterize storage-induced solubility changes in milk protein concentrate. However, fluorescence intensity from Maillard browning products can increase based on Maillard reaction-inducing environment and processing conditions such as storage time and temperature exposure history of permeate powders (Birlouez-Aragon et al., 2002). Therefore, Maillard browning products may not be suited as the fluorophore of interest for protein leak detection and were not considered for further chemometric analysis in this experiment. A similar trend between the appearances of riboflavin and Maillard browning products in EEM was also observed in Figures $6 \mathrm{C}$ and $6 \mathrm{D}$ for milk permeates.

Two regions in the permeate EEM correspond to tryptophan fluorescence, labeled as T1 and T2 in Figure $6 \mathrm{~A}$. The $\mathrm{T} 1$ region, with intensity maxima at $\lambda_{\mathrm{Ex}}$ $280 \mathrm{~nm}$ and $\lambda_{\mathrm{Em}} 340 \mathrm{~nm}$, is commonly measured in FFFS analysis of food products (Karoui and Blecker, 2011). This tryptophan region has been reported as an indicator for classifying cheese origins and storage effects on nonfat dry milk (Karoui et al., 2006; Liu and Metzger, 2007). Region T2 (Figure 6A), with maxima $\lambda_{\mathrm{Ex}} 225 \mathrm{~nm}$ and $\lambda_{\mathrm{Em}} 340 \mathrm{~nm}$, has been reported as the tryptophan side chain fluorescence corresponding to tryptophan-containing peptides (Baker, 2005). Whey permeate (Figure 6B) and milk permeate (Figure 6D) indicated high fluorescence intensities in both $\mathrm{T} 1$ and T2 regions for the HTP permeates, compared with 
the LTP permeates. The consistent intensity difference between HTP and LTP permeates indicated that tryptophan has potential as the fluorophore of interest for protein leak detection. To enrich the spectral information collected, tryptophan excitation spectra can highlight both tryptophan peak intensities with a single scan.

Excitation Spectra of Tryptophan. Tryptophan excitation spectra were collected based on the intensity maxima found from excitation-emission matrices, shown in Figures 6A through 6D. Figure 7A shows representative baseline-corrected excitation spectra $\left(\lambda_{\mathrm{Em}}\right.$ at $340 \mathrm{~nm}$ ) of LTP and HTP permeates, characterizing the spectral variation in both tryptophan regions. The maximum fluorescence intensity was found at $227 \mathrm{~nm}$, and spectral variation occurred at $220-225 \mathrm{~nm}$ and 260-290 $\mathrm{nm}$. The intensity maxima region from 260 to
$290 \mathrm{~nm}$ corresponds to tryptophan-containing proteins found in dairy products (Karoui and Blecker, 2011). Baker (2005) reported that fluorescence maxima from 220 to $225 \mathrm{~nm}$ represent the tryptophan-containing amino acids and peptides. The 2 tryptophan regions reported by Baker agreed with the EEM in the present study, and the tryptophan fluorescence spectra can characterize the protein leak in UF permeates. The spectral variation discovered in our experiment showed a similar trend (Figure 7B), with less variation observed in the high- and low-peptide permeates, corresponding to the TEP difference characterized by FFFS (region T2). Therefore, in our chemometric analysis, we used tryptophan excitation spectra as inputs to classify HTP and LTP permeates, high- and low-peptide permeates, and presence or absence of $\alpha$-LA or $\beta$-LG in permeates, and to quantify TP content in permeates.
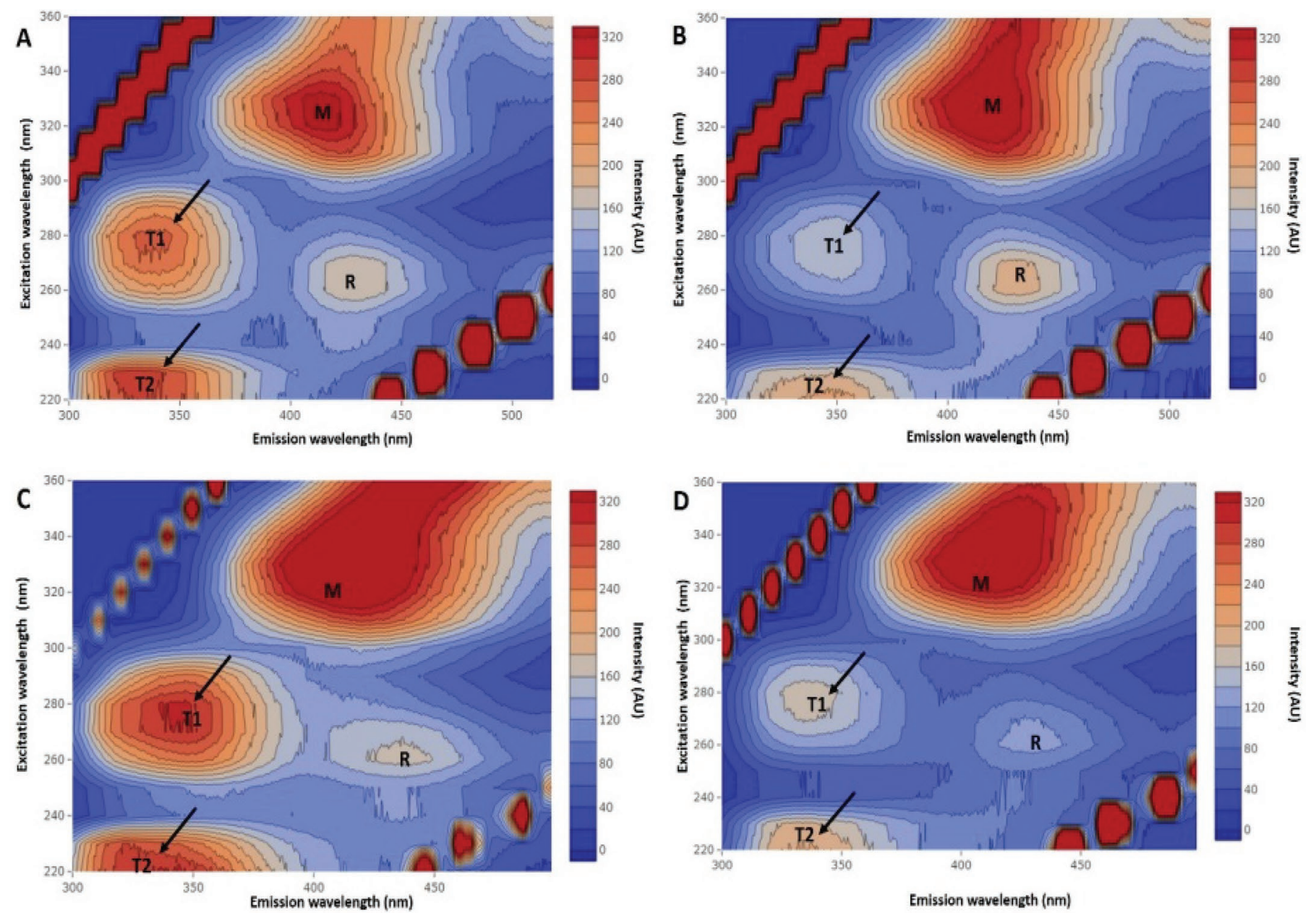

Figure 6. Excitation-emission matrices of (A) high-true protein (TP) whey permeate, (B) low-TP whey permeate, (C) high-TP milk permeate, and (D) low-TP milk permeate. Area T1: tryptophan fluorescence from protein; area T2: tryptophan fluorescence from peptides; area M: Maillard browning products; area R: riboflavin. Arrows point to the major intensity differences among the samples. 


\section{Chemometric Analysis}

Principal Component Analysis. Tryptophan excitation spectra were used to extract principal components. The first, second, and third principal components (PC1, PC2, and PC3) explained 95\% of the spectral variation in the tryptophan excitation spectra. In Figure $8 \mathrm{~A}$, the similarity plot using $\mathrm{PC} 1$ and $\mathrm{PC} 2$ is shown to characterize TP changes among permeate samples. Based on the differences highlighted from tryptophan peak intensities in Figure 7A, the TP difference among the permeates can be described by the arrow shown on Figure 8A. Variations in fluorescence intensity came from both protein and TEP contents in the permeates, as they contribute to TP content measured by the Kjeldahl method. In various studies based on tryptophan fluorescence spectra (Kulmyrzaev et al., 2005; Karoui et al., 2006), PCA has shown robust dimension reduction. Data obtained from the present study confirmed tryptophan fluorescence as a reliable source to quantify dairy proteins. The overall $\mathrm{TP}$ increase trend from PCA also indicated potential supervised regression prediction for TP contents in permeates.

In Figure 8B, the low- and high-peptide permeate classifications are used to label the similarity map. After preliminary visual comparison, $\mathrm{PC} 1$ and $\mathrm{PC} 3$ were used to best visualize the different types of permeates based on TEP contents. From Figure 8B, we observe that the high- and low-peptide permeates are not well separated using PCA, with some low-peptide permeates found in the high-peptide cluster. Connecting to Figure $7 \mathrm{~B}$, the peptide fluorescence intensity differences are not reflected as clearly as the TP difference due to the tryptophan-containing protein's signal interference with the peptide. However, fluorescence spectra are sensi- tive enough to differentiate peptide and whey protein compositions from the permeate source. The clusters observed in the similarity plot indicate the feasibility of classification models to predict low- or high-peptide permeate for unknown sources.

In Figure 8C, PC1 and $\mathrm{PC} 2$ provided visualization of the presence or absence of $\alpha-\mathrm{LA}$ and $\beta-\mathrm{LG}$ among the permeate samples. Overall, PCA was able to distinguish the permeates with full proteins from those containing only fragments of protein or peptides. The fluorescence signal difference for the presence of full proteins can be related to the quenching of tryptophan, and according to Chen and Barkley (1998), the side chain of tryptophan can alter the fluorescence signal in proteins. In this study, fluorescence spectroscopy can distinguish the $\alpha$-LA or $\beta$-LG corresponding side chains' difference from the rest of the proteinaceous matter. The clear separation of the 2 groups also allows supervised classification for detection of $\alpha$-LA or $\beta$-LG presence in permeate samples.

Partial Least Squares Regression. We used PLSR to predict TP content in permeate, and Figure 9 provides the visualization of the prediction accuracy with external validation. The calibration model was established using 6 latent variables, and the RMSECV of the model was $0.20 \%$ (Figure 9A). An RPD of 2.6 was found from the calibration model; according to Williams and Norris (2001), an RPD above 2 provides some practical applications for quality control purposes. The external validation yielded a RMSEP of 0.22 and an RPD of 2.8, showing that the calibration model is robust to test new samples (Figure 9B). The model developed using tryptophan excitation spectra can provide rapid estimation to the UF membrane processing industry. Kulmyrzaev et al. (2005) quantified the
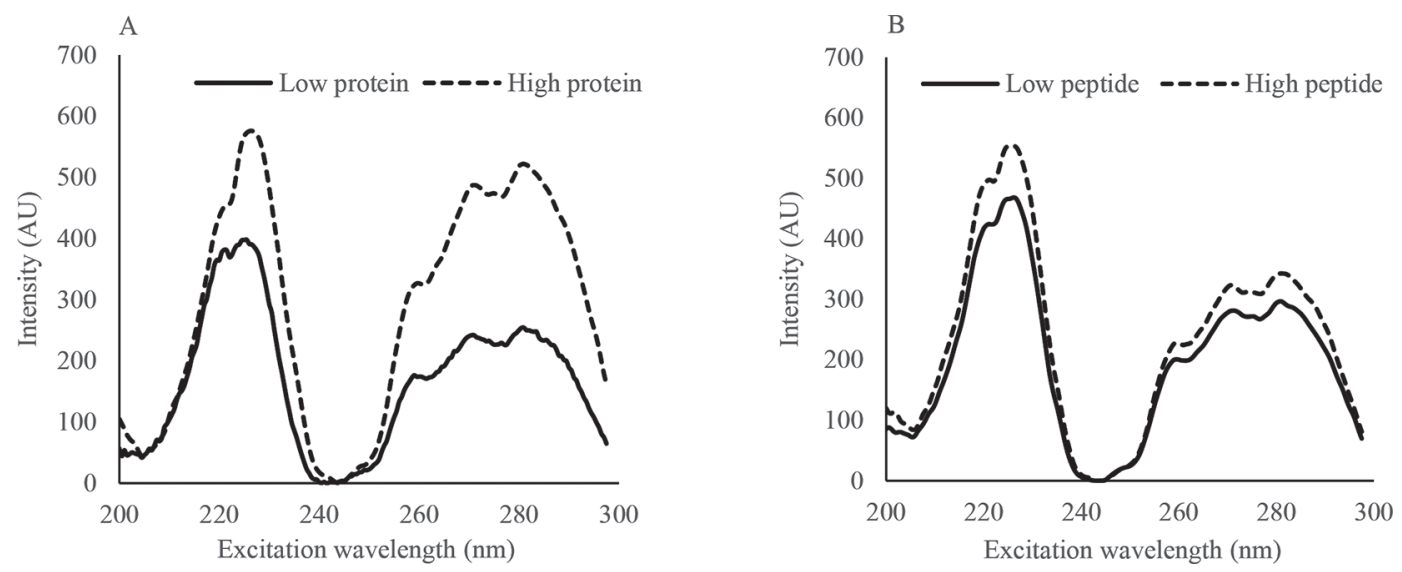

Figure 7. Representative tryptophan excitation fluorescence spectra of (A) low-protein (solid line) and high-protein (dashed line) permeates and (B) low-peptide (solid line) and high-peptide (dashed line) permeates. 

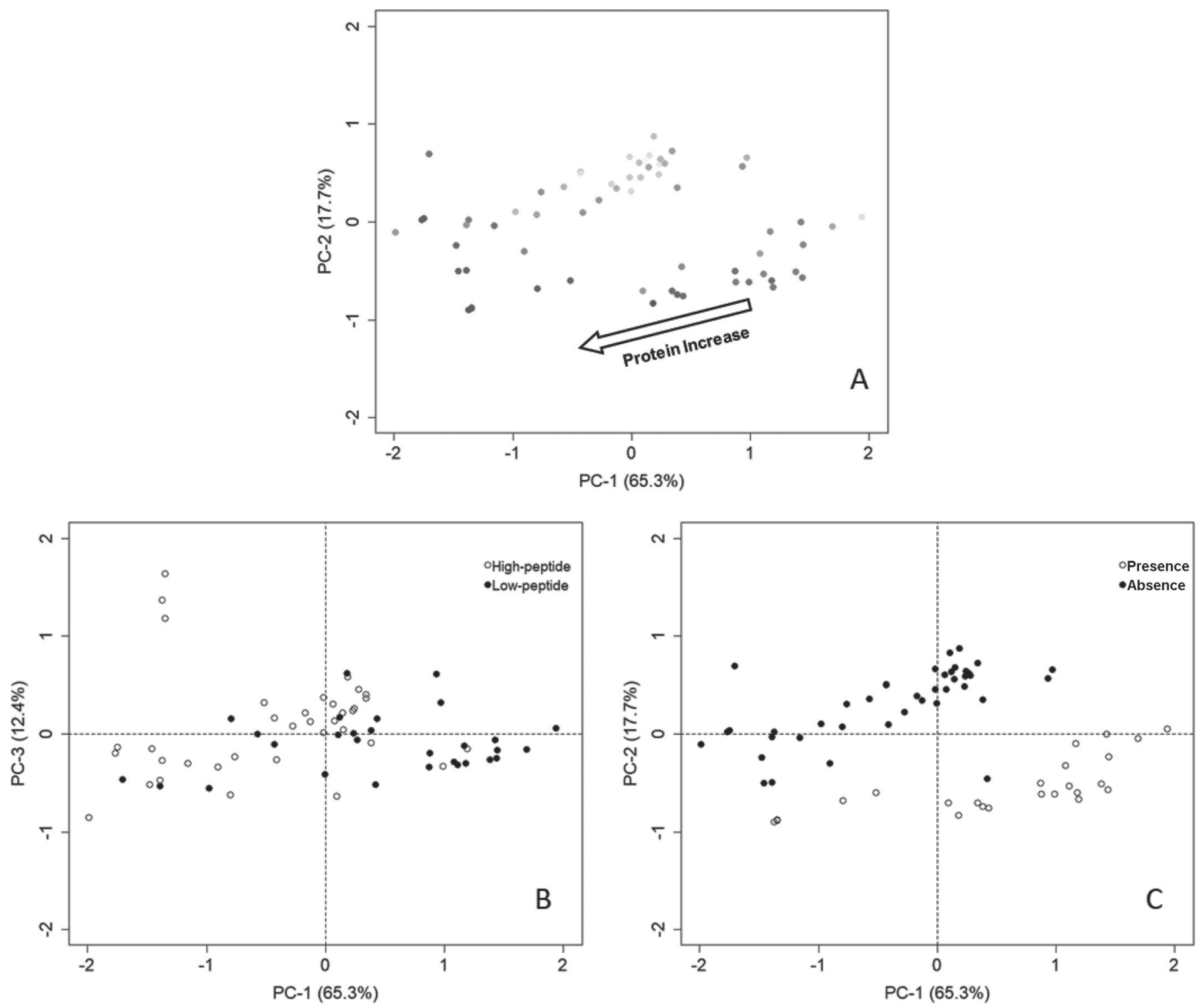

Figure 8. Principal component (PC) analysis similarity plots showing (A) comparison of high- and low-protein permeates (darker shading indicates higher true protein content), (B) comparison of high- and low-peptide permeates, and (C) presence or absence of full whey proteins $(\alpha-\mathrm{LA}$ and $\beta-\mathrm{LG})$ in permeate samples.

specific fraction of milk protein using fluorescence and PLSR, but the predictions were only useful for alkaline phosphatase and $\beta$-LG. In the present study, TP value measured by the Kjeldahl method seeks for less specificity but more accuracy toward estimating the overall proteinaceous matter in the permeate samples.

Partial Least Squares Discriminative Analysis. Because quantification may not be necessary when monitoring protein leakage during UF, classification methods provide simpler outcomes and easy-to-interpret results. In Table 1, the LTP and HTP permeate are predicted and cross-validated using PLS-DA. The accuracy of the model was $83.3 \%$, with sensitivity of 0.75 and specificity of 0.90 . The sensitivity showed the model's ability to successfully distinguish true HTP among all samples, and the specificity indicates the probability to confirm true LTP samples. Because the specificity is greater than the sensitivity, the classification error tends to predict false positives, meaning LTP misclassified as HTP samples (Ballabio and Consonni, 2013). Overall, the PLS-DA model provides useful prediction accuracy for quality control purposes. The 
Table 1. Sensitivity, specificity, and classification error of partial least squares discriminant analysis models for true protein level, peptide level, and full whey protein presence

\begin{tabular}{llccc}
\hline Classification & Class & Sensitivity & Specificity & Accuracy $(\%)$ \\
\hline True protein & Low/high & 0.75 & 0.90 & 83.3 \\
Peptide & Low/high & 0.91 & 0.78 & 84.8 \\
Full whey protein & Presence/absence & 1.00 & 0.98 & 98.5 \\
\hline
\end{tabular}

flagged potential HTP products can be further tested with reference methods to confirm the protein leaks during UF.

To examine the specific leaked proteinaceous matter, Table 1 provides the predictions for TEP contents and full whey protein presence. The accuracy for TEP content classification (low vs. high) was $84.8 \%$, with a sensitivity of 0.91 and specificity of 0.78 . The TEP content prediction can serve as an indicator of the quality of the UF feed, and possible proteolysis from bacteria and enzyme residuals may lead to high peptide content in permeates. Unlike the TP prediction, the specificity of the PLS-DA model is lower than its sensitivity, meaning that the model error comes from falsely classifying high-peptide samples as low-peptide, resulting in type II errors (Ballabio and Consonni, 2013). Connecting to the TEP discussion, the reference method for measuring peptides can be improved in the future, to fully characterize the presence of high peptide content in permeates. The present method can successfully recognize permeates with $\alpha$-LA or $\beta$-LG presence, with an accuracy of $98.5 \%$, sensitivity of 1.0 , and specificity of 0.98 . These results agree with previous studies of fluorescence spectroscopy characterizing proteins in dairy foods (Babu and Amamcharla, 2018).
Our model is capable of monitoring the presence of full proteins, which can be an indicator of membrane processing quality. This accurate method to measure full protein presence can help manufacturers monitor UF processing and control production quality.

\section{CONCLUSIONS}

In this study, protein leaks in UF permeates of whey and milk were characterized by various proteinaceous matter (e.g., TP, NPN, TEP, $\alpha-L A$, and $\beta-L G$ ). Use of FFFS revealed available fluorophores in UF permeates and identified tryptophan as the fluorophore of interest for protein leak detection during UF. Chemometric analysis of the tryptophan excitation spectra classified permeates based on their TP, TEP, and $\alpha$-LA or $\beta$-LG presence. The cross-validated prediction methods yielded a useful quantification of TP in permeates, and the classification methods were able to detect high TP level, high TEP level, and presence of $\alpha$-LA or $\beta$-LG, with $83.3 \%, 84.8 \%$, and $98.5 \%$ accuracy, respectively. The FFFS-based method can further be adapted to at-line and in-line modules in membrane processing plants. Manufacturers can sample UF permeate at different stages of processing and analyze its tryptophan
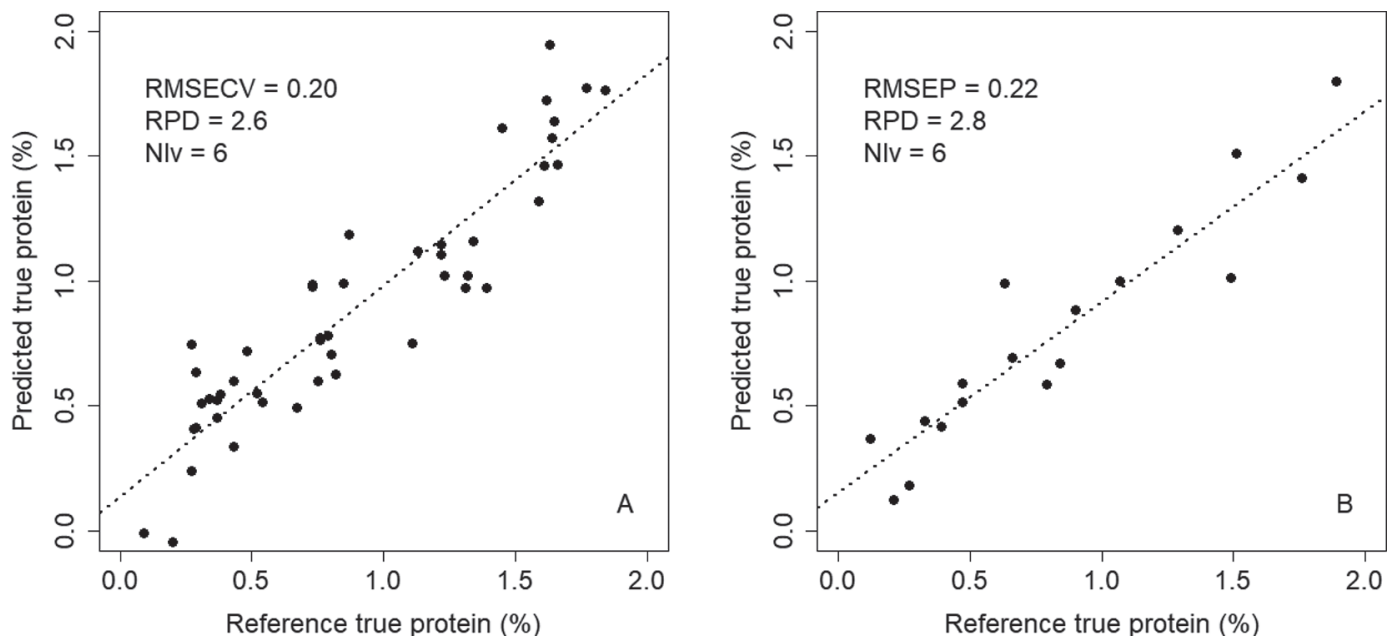

Figure 9. (A) Calibration model: reference true protein value vs. partial least squares regression predictions of permeate samples. (B) Validation model: reference true protein value vs. partial least squares regression predictions of permeate samples. The dashed line indicates the least squares fit of the predictions. Nlv = number of latent variables; RMSECV = root mean square error of cross validation; RMSEP $=$ root mean square error of prediction; RPD = ratio of prediction to deviation. 
excitation spectra at $25^{\circ} \mathrm{C}$. Calibrated chemometric models can rapidly predict occurrences and types of protein leaks.

\section{ACKNOWLEDGMENTS}

This project is Kansas State Research and Extension contribution number 19-236-J (Kansas State University, Manhattan). We thank Midwest Dairy Foods Research Center (St. Paul, MN) for their partial financial support.

\section{REFERENCES}

ADPI (American Dairy Products Institute). 2018. Dairy permeate standard. Accessed Oct.15, 2018. https://www.adpi.org/Portals/ 0/Standards/DairyPermeateStandard_book.pdf

Andersen, C. M., and G. Mortensen. 2008. Fluorescence spectroscopy: A rapid tool for analyzing dairy products. J. Agric. Food Chem. $56: 720-729$.

AOAC International. 2016. Official Methods of Analysis. 20th ed. AOAC International, Gaithersburg, MD.

Babu, K. S., and J. K. Amamcharla. 2018. Application of front-face fluorescence spectroscopy as a tool for monitoring changes in milk protein concentrate powders during storage. J. Dairy Sci. 101:10844-10859.

Baker, A. 2005. Thermal fluorescence quenching properties of dissolved organic matter. Water Res. 39:4405-4412.

Ballabio, D., and V. Consonni. 2013. Classification tools in chemistry. Part 1: Linear models. PLS-DA. Anal. Methods 5:3790-3798.

Birlouez-Aragon, I., P. Sabat, and N. Gouti. 2002. A new method for discriminating milk heat treatment. Int. Dairy J. 12:59-67.

Bonfatti, V., L. Grigoletto, A. Cecchinato, L. Gallo, and P. Carnier. 2008. Validation of a new reversed-phase high-performance liquid chromatography method for separation and quantification of bovine milk protein genetic variants. J. Chromatogr. A 1195:101-106.

Chen, Y., and M. D. Barkley. 1998. Toward understanding tryptophan fluorescence in proteins. Biochemistry. 37:9976-9982.

Diez, R., M. C. Ortiz, L. Sarabia, and I. Birlouez-Aragon. 2008. Potential of front face fluorescence associated to PLS regression to predict nutritional parameters in heat treated infant formula models. Anal. Chim. Acta 606:151-158.

Fagan, C. C., T. G. Ferreira, F. A. Payne, C. P. O'Donnell, D. J. O'Callaghan, and M. Castillo. 2011. Preliminary evaluation of endogenous milk fluorophores as tracer molecules for curd syneresis. J. Dairy Sci. 94:5350-5358.

Fox, P. F. 1989. Proteolysis during cheese manufacture and ripening1. J. Dairy Sci. 72:1379-1400.

Frankowski, K. M., R. E. Miracle, and M. A. Drake. 2014. The role of sodium in the salty taste of permeate. J. Dairy Sci. 97:5356-5370.

Gromski, P. S., E. Correa, A. A. Vaughan, D. C. Wedge, M. L. Turner, and R. Goodacre. 2014. A comparison of different chemometrics approaches for the robust classification of electronic nose data. Anal. Bioanal. Chem. 406:7581-7590.

Karoui, R., and C. Blecker. 2011. Fluorescence spectroscopy measurement for quality assessment of food systems - A review. Food Bioprocess Technol. 4:364-386.

Karoui, R., A. M. Mouazen, E. Dufour, R. Schoonheydt, and J. De Baerdemaeker. 2006. Utilisation of front-face fluorescence spec- troscopy for the determination of some selected chemical parameters in soft cheeses. Lait 86:155-169.

Kuhn, M. 2008. Caret package. J. Stat. Softw. 28:1-26.

Kulmyrzaev, A. A., D. Levieux, and É. Dufour. 2005. Front-face fluorescence spectroscopy allows the characterization of mild heat treatments applied to milk. Relations with the denaturation of milk proteins. J. Agric. Food Chem. 53:502-507.

Lenhardt, L., R. Bro, I. Zeković, T. Dramićanin, and M. D. Dramićanin. 2015. Fluorescence spectroscopy coupled with PARAFAC and PLS DA for characterization and classification of honey. Food Chem. 175:284-291.

Li, B., H. Wang, Q. Zhao, J. Ouyang, and Y. Wu. 2015. Rapid detection of authenticity and adulteration of walnut oil by FTIR and fluorescence spectroscopy: A comparative study. Food Chem. 181:25-30.

Liu, J., A. Zamora, M. Castillo, and J. Saldo. 2018. Modeling of the changes in bovine milk caused by ultra-high pressure homogenization using front-face fluorescence spectroscopy. J. Food Eng. 233:88-97.

Liu, X., and L. E. Metzger. 2007. Application of fluorescence spectroscopy for monitoring changes in nonfat dry milk during storage. J. Dairy Sci. 90:24-37.

Mevik, B. H., and R. Wehrens. 2007. The pls package: Principal component and partial least squares regression in R. J. Stat. Softw. 18. https://doi.org/10.18637/jss.v018.i02.

Minervini, F., F. Algaron, C. G. Rizzello, P. F. Fox, V. Monnet, and M. Gobbetti. 2003. Angiotensin i-converting-enzyme-inhibitory and antibacterial peptides from lactobacillus helveticus pr4 proteinase-hydrolyzed caseins of milk from six species. Appl. Environ. Microbiol. 69:5297-5305.

Oh, N. S., H. A. Lee, J. Y. Lee, J. Y. Joung, K. B. Lee, Y. Kim, K. W. Lee, and S. H. Kim. 2013. The dual effects of Maillard reaction and enzymatic hydrolysis on the antioxidant activity of milk proteins. J. Dairy Sci. 96:4899-4911.

R Core Team. 2019. R: A Language and Environment for Statistical Computing. R Foundation for Statistical Computing, Vienna, Austria.

Royer, C. A. 2006. Probing protein folding and conformational transitions with fluorescence. Chem. Rev. 106:1769-1784.

Shaikh, S., and C. O'Donnell. 2017. Applications of fluorescence spectroscopy in dairy processing: A review. Curr. Opin. Food Sci. $17: 16-24$.

Sithole, R., M. R. McDaniel, and L. M. Goddik. 2005. Rate of Maillard browning in sweet whey powder. J. Dairy Sci. 88:1636-1645.

Smith, S. T., L. Metzger, and M. A. Drake. 2016. Evaluation of whey, milk, and delactosed permeates as salt substitutes. J. Dairy Sci. 99:8687-8698.

Udenfriend, S., S. Stein, P. Böhlen, W. Dairman, W. Leimgruber, and M. Weigele. 1972. Fluorescamine: A reagent for assay of amino acids, peptides, proteins, and primary amines in the picomole range. Science 178:871-872.

Vivian, J. T., and P. R. Callis. 2001. Mechanisms of tryptophan fluorescence shifts in proteins. Biophys. J. 80:2093-2109.

Walstra, P., T. J. Geurts, A. Noomen, A. Jellema, and M. A. J. S. Van Boekel. 2005. Chapter 1: Milk-Composition, structure, and properties. Pages 1-24 in Dairy Technology: Principles of Milk Properties and Processes. Marcel Dekker Inc., New York, NY.

Williams, P., and K. Norris. 2001. Near-Infrared Technology in the Agricultural and Food Industries. 2nd ed. P. Williams and K. Norris, ed. AACC, St. Paul, MN.

Wold, S., M. Sjöström, and L. Eriksson. 2001. PLS-regression: A basic tool of chemometrics. Chemometr. Intell. Lab. 58:109-130. 